\title{
Competitiveness of economic zones and industrial zones: A comparative study between Vietnam and ASEAN countries
}

\author{
Le Thi Le ${ }^{1}{ }^{*}$, Hieu Tien Nguyen ${ }^{2}$, Chien Minh Le ${ }^{3}$, Cuong Quoc Nguyen ${ }^{1}$ \\ 1 Thu Dau Mot University, Binh Duong, Vietnam \\ ${ }^{2}$ Board of Management, Nghi Son economic zone, Thanh Hoa, Vietnam \\ ${ }^{3}$ Agency for Enterprise Development, Hanoi, Vietnam
}

\section{ARTICLE INFO}

Article history:

Received 21st Apr. 2021

Revised $16^{\text {th }}$ July 2021

Accepted 06 ${ }^{\text {th }}$ Aug. 2021

Keywords:

Board of management,

Nghi Son economic zone,

Thanh Hoa province.

\section{ABSTRACT}

Competitiveness plays a crucial role in attracting investors and supporting them to operate effectively when investing in economic zones and industrial zones (EZs, IZs). This study is conducted to compare the competitiveness of EZs and IZs in Vietnam to those in other ASEAN countries. This points out the strengths that need to be promoted, weaknesses that need to be overcome for the EZs and IZs in Vietnam. Both qualitative and quantitative research methods are applied. Data is collected from many reliable sources such as reports of the World Bank (WB), United Nations Conference on Trade and Development (UNCTAD). Data screening, processing and analyzing give the following specific results: Firstly, the ability to support business start-ups, tax and social obligations, and support to resolve corporate bankruptcy are considered as the biggest weaknesses of the EZs and IZs in Vietnam. Secondly, the ability to support various types of permits, support for access to input resources and credit access are the areas that need to be further improved in the future.

Copyright (C) 2021 Hanoi University of Mining and Geology. All rights reserved.

${ }^{*}$ Corresponding author

E- mail: letl@tdmu.edu.vn

DOI: 10.46326/JMES.2021.62(4).07 


\title{
Tạp chí Khoa học Kỹ thuật Mỏ - Địa chất
}

Trang điện tử: http://tapchi.humg.edu.vn

\section{Khả năng cạnh tranh của các khu kinh tế, khu công nghiệp: Nghiên cứu so sánh giữa Việt Nam và các nước ASEAN}

\author{
Lê Thị Lệ $1{ }^{1}{ }^{*}$, Nguyễn Tiến Hiệu ${ }^{2}$, Lê Minh Chiến ${ }^{3}$, Nguyễn Quốc Cường ${ }^{1}$ \\ 1 Trường Đại học Thủ Dầu Một, Bình Dưong, Việt Nam \\ ${ }^{2}$ Ban Quản lý Khu kinh tế Nghi Sơn, Thanh Hóa, Việt Nam \\ ${ }^{3}$ Cục phát triển doanh nghiệp, Hà Nội, Việt Nam
}

THÔNG TIN BÀI BÁO T TÓM TẮT

Quá trình:

Nhận bài 21/4/2021

Sửa xong 16/7/2021

Chap nhận đăng 06/8/2021

Từ khóa:

ASEAN,

Cạnh tranh,

Khu công nghiệp,

Khu kinh tế.
Khả năng cạnh tranh đóng vai trò quan trọng trong việc thu hút các nhà đầu tư và hố trợ các doanh nghiệp hoạt động hiệu quả khi đầu tư vào khu kinh tế, khu công nghiêpp (KKT, KCN). Nghiên cứu này được thực hiện nhằm so sánh khả năng cạnh tranh của các KKT, KCN ở Việt Nam với các nước thuốc ASEAN,tù đó chỉ ra các điểm mạnh cần phát huy, điểm yếu cần khắc phuc đối với các KKT, KCN ở Việt Nam. Cả hai phương pháp nghiên cứu định tính và định lượng đã được áp dụng. Dũ liẹu được thu thập tù̀ nhiều nguồn đánh tin cậy như báo cáo của Ngân hàng thế giới (WB), Hội nghi Liên Hiệp Quốc về Thương mai và Phát triển (UNCTAD),... Dũ liệu sau khi sàng lọc, được xử lý và cho ra các kết quả cu thể: khả năng hỗ trợ khởi sự kinh doanh; nộp thuế và các nghĩa vu xã hội; hỗ trơ giải quyết phá sản doanh nghiệp được xem nhu những điểm yếu lớn nhất của các KKT, KCN ở Việt Nam hiện nay. Khả năng hỗ trợ xin các loại giấy phép, hỗ trợ tiếp cận nguồn lực đầu vào và hỗ trợ tiếp cận tín dụng là nhũng khía cạnh cần tiếp tục cải thiện trong thời gian tới.

(C) 2021 Trường Đại học Mỏ - Địa chất. Tất cả các quyền được bảo đảm.

\section{Mở đầu}

Trong bối cảnh cạnh tranh gay gắt giữa các khu kinh tế (KKT), khu công nghiệp (KCN) ở trong khu vực Đông Nam Á (ASEAN) nói riêng và toàn thế giới nói chung, nhằm thu hút dòng vốn đầu tư rút ra từ Trung Quốc khi mà cuộc chiến thương mại Mỹ - Trung đang ngày càng trở nên gay gắt và

*Tác giả liên hệ

E-mail: letl@tdmu.edu.vn

DOI: 10.46326/JMES.2021.62(4).07 chưa có dấu hiệu dừng lại, vấn đề nâng cao khả năng cạnh tranh của các KKT, KCN lại càng trở nên cấp thiết (Aggarwal, 2019). Đến nay, khu vực Đông Nam Á có khoảng 1720 khu kinh tế và khu công nghiệp (UNIDO, 2019). Với nhiều hình thức đa dạng như: khu kinh tế đặc biệt (SEZs), khu thương mại tự do (FTZ), khu chế xuất (KCX), khu công nghiệp (KCN), khu công nghiệp sinh thái (EIP), khu công nghệ (TP) và khu đổi mới sáng tạo (ID). Tùy thuộc vào đặc thù cụ thể về mức độ phát triển, điều kiện nguồn lực và chiến lược cạnh tranh thu hút FDI, mỗi quốc gia lại có sự tập trung khác nhau vào các loại KKT, KCN kể trên (Ayman, 
2020). Các KKT, KCN này được coi là công cụ quan trọng không chỉ để thúc đẩy xuất khẩu và thu ngoại tệ mà còn để kích thích tăng trưởng kinh tế thông qua đầu tư bổ sung, chuyển giao công nghệ và tạo việc làm (Farole and Akinci, 2011).

Tuy được chú trọng thúc đẩy hình thành và mở rộng, nhưng khả năng cạnh tranh của các KKT, KCN ở các nước thuộc ASEAN lại không đồng đều (Aggarwal, 2019). Singapore được xem là hình mẫu tiêu biểu cho việc phát triển các $\mathrm{KKT}, \mathrm{KCN}$; Ngược lại, Philippines tuy có số lượng KKT, KCN khá lớn, nhưng hiệu quả hoạt động lại rất kém. Bên cạnh đó, đa phần các KKT vẫn chủ yếu dựa vào yếu tố miễn giảm thuế phí, lao động giá rẻ để thu hút các doanh nghiệp đầu tư nước ngoài, thiếu các phương án hỗ trợ các doanh nghiệp hoạt động hiệu quả trong dài hạn để khai thác tối đa các doanh nghiệp lớn đã đầu tư, cũng như tạo nền tảng thu hút các doanh nghiệp mới trong những lĩnh vực có giá trị gia tăng cao (Đỗ Minh Triết, 2019).

Liên quan đến khía cạnh học thuật, đã có nhiều nghiên cứu ở trong và ngoài nước phân tích nội dung về thang đo đánh giá khả năng cạnh tranh của các KKT, KCN (Nguyễn Tiến Hiệu, Lê Thị Lệ, 2021). Tuy nhiên, các nghiên cứu đa phần chỉ tập trung vào các yếu tố mang tính lợi thế đặc trưng của KKT, KCN đó. Chưa có thang đo nào được thực hiện tập trung vào khía cạnh khả năng hỗ trợ doanh nghiệp đầu tư và hoạt động tại KKT, KCN (Bogoviz và nnk., 2016; Wang, 2013; Ishida, 2009).

Từ các vấn đề cấp thiết ở trên, dựa trên những thông tin thứ cấp thu thập từ nhiều nguồn, nghiên cứu này được thực hiện nhằm hai mục tiêu: thứ nhất, phân tích so sánh các cơ chế hố trợ doanh nghiệp, từ đó làm rõ mức độ cạnh tranh giữa các KKT, KCN giữa Việt Nam và các nước ASEAN; thứ hai, đề xuất các hàm ý chính sách nhằm hỗ trợ các KKT, KCN ở Việt Nam nâng cao khả năng hỗ trợ doanh nghiệp, từ đó cải thiện khả năng cạnh tranh trong thời gian tới.

\section{Tổng quan nghiên cứu}

KKT, KCN được hiểu là khu vực có không gian kinh tế riêng biệt với môi trường đầu tư và kinh doanh đặc biệt thuận lợi cho các nhà đầu tư, có ranh giới địa lý xác định, được thành lập theo điều kiện, trình tự và thủ tục quy định của nước sở tại (Nghị định chính phủ, 2018). Các đặc điểm chính của KKT, KCN thành công liên quan đến khả năng cung cấp ngay các cơ sở hạ tầng chất lượng cao, nguồn nhân lực kỹ năng cao sẵn có, và các dịch vụ hỗ trợ rõ ràng (Zeng, 2010). Bên cạnh đó, việc thực thi pháp lý được sắp xếp hợp lý, các quy tắc thành lập doanh nghiệp đơn giản; quản lý hải quan, quản lý hành chính và các hình thức phê duyệt đặc biệt khác được hỗ trợ thực hiện nhanh chóng cũng là những đặc điểm quan trọng để tạo nên sự thành công cho các KKT, KCN (Wahyuni và nnk., 2010).

Khả năng cạnh tranh của KKT, KCN được hiểu là tổng hòa của các yếu tố nhằm thu hút và hỗ trợ các doanh nghiệp hoạt động hiệu quả khi đầu tư vào $\mathrm{KKT}, \mathrm{KCN}$ đó (Porter, 2011; Hsu và nnk., 2013). Một KKT, KCN được xem là có khả năng cạnh tranh cao khi sở hữu một chính sách thu hút đầu tư thông thoáng, linh hoạt; các quy trình thủ tục đầu tư nhanh gọn, chi phí thấp; có khả năng cung cấp nhanh chóng các nguồn lực đầu vào (lao động, cơ sở hạ tầng, vốn tín dụng,...) mà doanh nghiệp cần khi khởi sự kinh doanh; cũng như có được sự thuận tiện trong việc thúc đẩy hoạt động xuất nhập khẩu hàng hóa vào/ra KKT, KCN đó (Farole, Akinci, 2011).

Liên quan đến thang đo đánh giá khả năng cạnh tranh của các KKT, KCN ở các nước, đa phần các nghiên cứu chỉ tập trung vào các yếu tố mang tính lợi thế đặc trưng của KKT, KCN đó, như: vị trí địa lý, tài nguyên tự nhiên (nhân công giá rẻ hoặc có trình độ tay nghề cao, tài nguyên thiên nhiên sẵn có), quy mô nền kinh tế, khả năng chi đầu tư cơ sở hạ tầng, và các ưu đãi về thuế. Đây là những khía cạnh mang tính cố định cao, khó thay đổi trong thời gian ngắn (Bogoviz và nnk., 2016; Wang, 2013; Ishida, 2009). Ngược lại, hầu như không có nghiên cứu nào tập trung vào khía cạnh khả năng hỗ trợ doanh nghiệp đầu tư và hoạt động của KKT, KCN đó. Vì vậy, trong khuôn khổ nghiên cứu này, bài báo tập trung vào khung phân tích về khả năng cạnh tranh được đề xuất bởi Ngân hàng Thế giới (WB) (Bảng 1).

Mục tiêu của khung phân tích này là cung cấp những thông tin rất chi tiết để các KKT, KCN xác định được những lĩnh vực nên cải cách và hoàn thiện. Qua việc so sánh dựa trên các tiêu chí trong khung phân tích này, có thể chỉ ra những thực tiễn tốt được triển khai. Từ đó, thúc đẩy việc học hỏi để tác động tích cực lên năng lực cạnh tranh, năng suất và hiệu quả của các KKT, KCN. Khung phân 
Bảng 1. Bộ chỉ tiêu so sánh khả năng cạnh tranh các KKT, KCN sau khi đã hiệu chỉnh tù̀ bước nghiên cúu định tính.

\begin{tabular}{|c|c|c|}
\hline Nhóm tiêu chí & Chỉ tiêu đo lường & $\begin{array}{l}\text { Chỉ tiêu bổ sung từ bước } \\
\text { nghiên cứu định tính }\end{array}$ \\
\hline $\begin{array}{l}\text { Hỗ trợ khởi sự kinh } \\
\text { doanh }\end{array}$ & $\begin{array}{l}\text { Khả năng hỗ trợ thực hiện thủ tục, thời gian, chi phí } \\
\text { và yêu cầu về vốn tối thiểu }\end{array}$ & $\begin{array}{l}\text { Khả năng rút ngắn/giảm số } \\
\text { bước thủ tục }\end{array}$ \\
\hline $\begin{array}{l}\text { Hỗ trợ xin các loại } \\
\text { giấy phép }\end{array}$ & $\begin{array}{l}\text { Thời gian và chi phí để hoàn thành tất cả các thủ tục } \\
\text { xin các loại giấy phép }\end{array}$ & $\begin{array}{l}\text { Khả năng rút ngắn/giảm số } \\
\text { bước thủ tục }\end{array}$ \\
\hline $\begin{array}{l}\text { Hỗ trợ tiếp cận } \\
\text { nguồn lực đầu vào }\end{array}$ & $\begin{array}{l}\text { Khả năng hỗ trợ/rút ngắn/giảm số thủ tục, thời gian, } \\
\text { chi phí để được cung cấp các cơ sở hạ tầng (điện, } \\
\text { nước) }\end{array}$ & $\begin{array}{l}\text { Thời gian, chi phí để được } \\
\text { cung cấp nguồn nhân lực }\end{array}$ \\
\hline $\begin{array}{l}\text { Hỗ trợ đăng ký tài } \\
\text { sản }\end{array}$ & $\begin{array}{l}\text { Khả năng hỗ trợ/rút ngắn/giảm số thủ tục, thời gian } \\
\text { và chi phí để chuyển nhượng tài sản }\end{array}$ & $\begin{array}{l}\text { Chất lượng quy định quản lý } \\
\text { hành chính về đất đai }\end{array}$ \\
\hline $\begin{array}{l}\text { Hỗ trợ tiếp cận tín } \\
\text { dụng }\end{array}$ & $\begin{array}{l}\text { Khả năng hỗ trợ thúc đẩy các giao dịch bảo đảm và } \\
\text { hệ thống thông tin tín dụng }\end{array}$ & \\
\hline Bảo vệ nhà đầu tư & $\begin{array}{l}\text { Khả năng hỗ trợ thúc đẩy các quyền của nhà đầu tư } \\
\text { trong giao dịch của các bên có liên quan }\end{array}$ & $\begin{array}{l}\text { Khả năng hỗ trợ thúc đẩy các } \\
\text { quyền của nhà đâuu tư trong } \\
\text { quản trị doanh nghiệp }\end{array}$ \\
\hline $\begin{array}{l}\text { Nộp thuế và các } \\
\text { nghĩa vụ xã hội }\end{array}$ & $\begin{array}{l}\text { Khả năng hỗ trợ/rút ngắn/giảm các loại thuế và số } \\
\text { lần nộp, thời gian, tổng mức thuế suất và các khoản } \\
\text { đóng góp (BHXH) của một doanh nghiệp, và chỉ số } \\
\text { sau nộp thuế }\end{array}$ & \\
\hline $\begin{array}{l}\text { Giao dịch thương } \\
\text { mại qua biên giới }\end{array}$ & $\begin{array}{l}\text { Khả năng hỗ trợ/rút ngắn/giảm thời gian, chi phí để } \\
\text { thực hiện thủ tục xuất nhập khẩu qua biên giới }\end{array}$ & \\
\hline $\begin{array}{l}\text { Giải quyết tranh } \\
\text { chấp hợp đồng }\end{array}$ & $\begin{array}{l}\text { Khả năng hỗ trợ/rút ngắn/giảm thời gian và chi phí } \\
\text { để giải quyết các tranh chấp thương mại, chỉ số chất } \\
\text { lượng quy trình tư pháp }\end{array}$ & \\
\hline $\begin{array}{l}\text { Giải quyết phá sản } \\
\text { doanh nghiệp }\end{array}$ & $\begin{array}{l}\text { Khả năng hỗ trợ, chi phí, kết quả và tỷ lệ thu hồi của } \\
\text { một vụ việc phá sản thương mại, chỉ số chất lượng } \\
\text { khung khổ pháp lý về giải quyết phá sản }\end{array}$ & $\begin{array}{l}\text { Khả năng rút ngắn/giảm thời } \\
\text { gian thu hồi của một vụ việc } \\
\text { phá sản thương mại }\end{array}$ \\
\hline
\end{tabular}

(Nguồn: WB, 2021; kết quả điều tra định tính, 2021)

tích này cũng hướng đến việc đánh giá một cách độc lập, khách quan thay vì hướng đến việc đề cao tính ưu việt của các KKT, KCN ở các nước phát triển như các thang đo đánh giá khác. Các chỉ số chủ yếu được đánh giá trên các tiêu chí: số lượng thủ tục, thời gian, chi phí và chỉ số đo lường chất lượng các quy định (Wahyuni và nnk., 2013).

\section{Phương pháp nghiên cứu}

Trong nghiên cứu này, các tác giả sử dụng đồng thời cả hai phương pháp: nghiên cứu định tính và nghiên cứu định lượng. Trước tiên bước nghiên cứu định tính thông qua phỏng vấn chuyên gia được thực hiện dựa trên phương pháp Delphi.
Cụ thể, đây là một quy trình được sử dụng để đưa ra ý kiến hoặc quyết định của nhóm bằng cách khảo sát một nhóm chuyên gia (8 người, bao gồm các nhà nghiên cứu có kinh nghiệm trong lĩnh vực nghiên cứu về cạnh tranh nói chung và cạnh tranh giữa các KKT, KCN nói riêng). Các chuyên gia trả lời một số vòng của bảng câu hỏi định tính và câu trả lời được tổng hợp và chia sẻ với nhóm sau mỗi vòng. Kết quả của bước điều tra định tính giúp: hiệu chỉnh khung phân tích đề xuất, các tiêu chí sử dụng để so sánh giữa các KKT, KCN ở các nước; và giải nghĩa các vấn đề của các KKT, KCN ở Việt Nam (Bảng 1). 
Tiếp đến, ở bước nghiên cứu định lượng, nhóm nghiên cứu tiến hành thu thập các dữ liệu thứ cấp từ nhiều nguồn khác nhau, như: bộ dữ liệu báo cáo về mức độ thuận lợi của môi trường kinh doanh (Ease of Doing Business) của Ngân hàng Thế giới (WB); các dữ liệu từ báo cáo về khả năng cạnh các KKT, KCN trong khu vực của AEC (Cộng đồng kinh tế ASEAN); các dữ liệu từ báo cáo phân tích về hoạt động phát triển môi trường kinh doanh ở các KKT, KCN Việt Nam của phòng Thương mại và Công nghiệp Việt Nam (VCCI) và Viện Nghiên cứu quản lý kinh tế Trung ương; cũng như các nguồn dữ liệu khác. Nhằm phân tích so sánh các cơ chế hỗ trợ doanh nghiệp, từ đó làm rõ mức độ cạnh tranh giữa các KKT, KCN giữa Việt Nam và các nước ASEAN, trong đó tập trung vào những nước có khả năng cạnh tranh với các KKT, KCN ở Việt Nam, gồm: Philippines, Thái Lan, Malaysia, Indonesia, Singapore và Campuchia.
Nhằm đảm bảo tính cập nhật, dữ liệu được thu thập chủ yếu trong giai đoạn 2015 đến 2021.

Liên quan đến phương pháp phân tích, dữ liệu sau khi được xác thực, sàng lọc và được tổng hợp thông quan phần mềm Nvivo 20, cũng như áp dụng một số phương pháp phân tích cơ bản như thống kê mô tả, thống kê so sánh và thống kê suy luận.

\section{Kết quả nghiên cứu}

\subsection{So sánh về quy mô các khu kinh tế, khu công nghiệp ở Việt Nam và các nước ASEAN}

Khả năng cạnh tranh của các KKT, KCN ở các nước ASEAN phần nào được phản ánh thông qua quy mô, lượng vốn FDI thu hút được và giá trị sản phẩm sản xuất (manufacturing products) xuất khẩu được. Trong đó, tổng giá trị xuất khẩu sản phẩm sản xuất được tính dựa trên tỷ trọng sản phẩm sản xuất và quy mô xuất khẩu của nước đó.

Kết quả ở Bảng 2, 3 và 4 cho thấy: Việt Nam,

Bảng 2. Bộ chỉ tiêu so sánh khả năng cạnh tranh các KKT, KCN.

\begin{tabular}{|c|c|c|c|c|}
\hline Quốc gia & Số lượng & $\begin{array}{c}\text { Lượng vốn FDI } \\
\text { (tỷ USD) }\end{array}$ & $\begin{array}{l}\text { Xuất khẩu sản phẩm } \\
\text { sản xuất (tỷ USD) } \\
\end{array}$ & $\begin{array}{l}\text { Các hình thức ưu đãi phổ } \\
\text { biến }\end{array}$ \\
\hline Việt Nam & $\begin{array}{l}18 \text { KKT ven biển; } 369 \text { KCN; } \\
3 \text { Khu công nghệ cao }\end{array}$ & 70,2 & 227,73 & $\begin{array}{l}\text { Miễn giảm thuế thu nhập } \\
\text { doanh nghiệp (TNDN) và } \\
\text { thuế thu nhập cá nhân }\end{array}$ \\
\hline Philippines & $\begin{array}{l}12 \text { KKT, } 300 \text { KCN; } 22 \text { KKT } \\
\text { Kinh doanh nông nghiệp; } 3 \\
\text { Khu công nghệ cao }\end{array}$ & 35,8 & 62,77 & $\begin{array}{l}\text { Miễn thuế nhập khẩu nguyên } \\
\text { liệu thô; miễn giảm đến thuế } \\
\text { TNDN; hỗ trợ cấp thị thực tối } \\
\text { đa }\end{array}$ \\
\hline Thái Lan & $\begin{array}{l}10 \text { KKT dọc biên giới; } 74 \\
\text { KCN; } 9 \text { Khu công nghệ cao }\end{array}$ & 34,2 & 192,31 & $\begin{array}{l}\text { Miễn giảm thuế TNDN thông } \\
\text { qua chính sách "Thailand } \\
\text { Plus" }\end{array}$ \\
\hline Malaysia & $\begin{array}{l}5 \text { hành lang đầu tư (loại KKT } \\
\text { kiểu mới); } 18 \text { KKT; } 304 \text { KCN; } \\
9 \text { Khu công nghệ cao }\end{array}$ & 46,1 & 180,95 & $\begin{array}{l}\text { Miễn thuế thu nhập trong } 10 \\
\text { năm; miến thuế đối với đất } \\
\text { đai, hạ tầng }\end{array}$ \\
\hline Indonesia & $\begin{array}{l}\text { 14 KKT đã thành lập; } 7 \text { KKT } \\
\text { đang xây dựng; } 329 \text { KCN; } 1 \\
\text { KCN sinh thái; } 4 \text { Khu công } \\
\text { nghệ cao }\end{array}$ & 85,1 & 92,89 & $\begin{array}{l}\text { Miễn giảm thuế TNDN } \\
\text { (TNDN) trong } 20 \text { năm trị giá } \\
\text { 1,4 tỷ USD }\end{array}$ \\
\hline Singapore & $\begin{array}{l}2 \text { KCN, } 2 \text { Khu công nghệ cao } \\
\text { tại Malaysia \& Indonesia; } 1 \\
\text { KCN sinh thái; } 1 \text { Khu đổi } \\
\text { mới sáng tạo }\end{array}$ & 381,0 & 304,85 & $\begin{array}{l}\text { Miễn thuế thu nhấp trong } 10 \\
\text { năm; miến thuế đối với đất } \\
\text { đai, hạ tầng }\end{array}$ \\
\hline Campuchia & $31 \mathrm{KKT}$ & 13,6 & 14,14 & $\begin{array}{l}\text { Miễn giảm thuế TNDN trong } \\
\text { tối đa } 9 \text { năm; miễn thuế xuất } \\
\text { nhập khẩu }\end{array}$ \\
\hline
\end{tabular}

(Nguồn: Ayman, 2020; UNIDO, 2019; UNCTAD, 2020; WB, 2021) 
Bảng 3. Tổng vốn đầu tu trực tiếp nước ngoài (FDI) vào các Khu kinh tế, Khu công nghiệp ở các nước ASEAN trong giai đoạn 2015 - 2019 (tỷ USD).

\begin{tabular}{|c|c|c|c|c|c|c|}
\hline & 2015 & 2016 & 2017 & 2018 & 2019 & Tổng \\
\hline Việt Nam & 11,8 & 12,6 & 14,1 & 15,5 & 16,2 & 70,2 \\
\hline Philippines & 5,6 & 8,3 & 10,3 & 6,6 & 5,0 & 35,8 \\
\hline Thái Lan & 8,9 & 2,8 & 8 & 10,4 & 4,1 & 34,2 \\
\hline Malaysia & 10,2 & 11,3 & 9,3 & 7,6 & 7,7 & 46,1 \\
\hline Indonesia & 16,6 & 3,9 & 20,6 & 20,6 & 23,4 & 85,1 \\
\hline Singapore & 59,7 & 73,9 & 75,7 & 79,7 & 92,0 & 381,0 \\
\hline Campuchia & 1,7 & 2,3 & 2,7 & 3,2 & 3,7 & 13,6 \\
\hline
\end{tabular}

(Nguồn: CARI Captures, 2020)

Bảng 4. Tổng giá trị sản phẩm sản xuất trong tổng kim ngạch xuất khẩu của các nước ASEAN năm 2019.

\begin{tabular}{|c|c|c|c|}
\hline & $\begin{array}{c}\text { Quy mô xuất khẩu } \\
(\text { Tỷ USD) }\end{array}$ & $\begin{array}{c}\text { Tỷ trọng sản phẩm } \\
\text { sản xuất }\end{array}$ & $\begin{array}{c}\text { Tổng giá trị sản phẩm sản xuất } \\
\text { (Tỷ USD) }\end{array}$ \\
\hline Việt Nam & 264,19 & $86,2 \%$ & 227,73 \\
\hline Philippines & 70.93 & $88,5 \%$ & 62,77 \\
\hline Thái Lan & 233.67 & $82,3 \%$ & 192,31 \\
\hline Malaysia & 238,09 & $76,0 \%$ & 180,95 \\
\hline Indonesia & 167,68 & $55,4 \%$ & 92,89 \\
\hline Singapore & 390,33 & $78,1 \%$ & 304,85 \\
\hline Campuchia & 14,82 & $95,4 \%$ & 14,14 \\
\hline
\end{tabular}

(Nguồn: TrendEconomy, 2021; ASEAN Secretariat 2020)

Indonesia và Philippines là ba nước có sự đầu tư lớn vào việc thúc đẩy phát triển các KKT, KCN. Singapore với đặc thù giới hạn về diện tích lãnh thổ nên việc phát triển khá hạn chế về số lượng. Tuy vậy, xét về khía cạnh hiệu quả, các KKT, KCN ở Singapore mang lại giá trị sản phẩm sản xuất để xuất khẩu cao nhất khu vực.

\subsection{Các chỉ số canh tranh tổng thể về mức độ hỗ trợ doanh nghiệp giữa các khu kinh tế, khu công nghiệp ở Việt Nam và các nước ASEAN}

Các chỉ số cạnh tranh tổng thể về mức độ hỗ trợ doanh nghiệp chỉ ra rằng: điểm mạnh tương đối của các KKT, KCN ở Việt Nam so với các nước ASEAN nằm ở khả năng hỗ trợ xin các loại giấy phép; hỗ trợ tiếp cận nguồn lực đầu vào và hỗ trợ tiếp cận tín dụng. Trong khi đó, khả năng hỗ trợ khởi sự kinh doanh; nộp thuế và các nghĩa vụ xã hội và giải quyết phá sản doanh nghiệp được xem như những điểm yếu lớn nhất.
Liên quan đến đánh giá so sánh nỗ lực cạnh tranh của các KKT, KCN ở các quốc gia có thể nhận thấy: các KKT, KCN ở Singapore hầu như dẫn đầu ở mọi chỉ số. So với các nước còn lại, các KKT, KCN ở Malaysia có điểm mạnh tương đối về khả năng hỗ trợ xin các loại giấy phép, hỗ trợ đăng ký tài sản; Thái Lan có điểm mạnh tương đối về khả năng hỗ trợ khởi sự kinh doanh, bảo vệ nhà đầu tư, nộp thuế và các nghĩa vụ xã hội; các KKT, KCN ở Philippines có điểm mạnh tương đối về khả năng hỗ trợ tiếp cận nguồn lực đầu vào; Indonesia có điểm mạnh tương đối về khả năng giải quyết phá sản; các KKT, KCN ở Campuchia có điểm mạnh về khả năng hỗ trợ tiếp cận tín dụng (Bảng 5).

\subsection{Các chỉ số canh tranh thành phần về múcc độ hỗ trợ doanh nghiệp giữa các khu kinh tế, khu công nghiệp ở Việt Nam và các nước ASEAN}

- Cạnh tranh về khả năng hỗ trợ khởi sự kinh doanh và hỗ trợ tiếp cận địa điểm (Bảng 6). 
Bảng 5. Chỉ số cạnh tranh chung về múc độ hỗ trọ̣ doanh nghiệp.

\begin{tabular}{|l|c|c|c|c|c|c|c|}
\hline & Việt Nam & Philippines & Thái Lan & Malaysia & Indonesia & Singapore & Campuchia \\
\hline Hỗ trợ khởi sự kinh doanh & 115 & 171 & 47 & 126 & 140 & $4^{*}$ & 187 \\
\hline Hỗ trợ xin các loại giấy phép & 25 & 85 & 34 & $2^{*}$ & 110 & 5 & 178 \\
\hline Hỗ trợ tiếp cận nguồn lực đầu vào & 27 & 32 & 6 & $4^{*}$ & 33 & 19 & 146 \\
\hline Hỗ trợ đăng ký tài sản & 64 & 120 & 67 & 33 & 106 & $21^{*}$ & 129 \\
\hline Hỗ trợ tiếp cận tín dụng & $25^{*}$ & 132 & 48 & 37 & 48 & 37 & $25^{*}$ \\
\hline Bảo vệ nhà đầu tư & 97 & 72 & 3 & $2^{*}$ & 37 & 3 & 128 \\
\hline Nộp thuế và các nghĩa vụ xã hội & 109 & 95 & 68 & 80 & 81 & $7^{*}$ & 138 \\
\hline Giao dịch thương mại qua biên giói & 104 & 113 & 62 & 49 & 116 & $47^{*}$ & 118 \\
\hline Giải quyết tranh chấp hợp đồng & 68 & 152 & 37 & 35 & 139 & $1^{*}$ & 182 \\
\hline Giải quyết phá sản DN & 122 & 65 & $24^{*}$ & 40 & 38 & 27 & 82 \\
\hline
\end{tabular}

Chú thích: * giá trị chỉ số tốt nhất trong số các quốc gia so sánh - theo tùng tiêu chí đánh giá

(Nguồn: WB, 2021)

Bảng 6. Cạnh tranh về khả năng hỗ trợ khởi sự kinh doanh và hỗ trợ tiếp cận địa điểm.

\begin{tabular}{|c|c|c|c|c|c|c|c|c|c|c|}
\hline \multirow[b]{2}{*}{ Quốc gia } & \multicolumn{3}{|c|}{$\begin{array}{l}\text { Khả năng hỗ trợ khởi sự } \\
\text { kinh doanh }\end{array}$} & \multicolumn{3}{|c|}{$\begin{array}{c}\text { Khả năng hỗ trợ xin các } \\
\text { loại giấy phép }\end{array}$} & \multicolumn{2}{|c|}{$\begin{array}{l}\text { Hỗ trợ tiếp cận } \\
\text { nguồn lực đầu } \\
\text { vào }\end{array}$} & \multicolumn{2}{|c|}{$\begin{array}{l}\text { Khả năng hỗ } \\
\text { trợ đăng ký } \\
\text { tài sản }\end{array}$} \\
\hline & $\begin{array}{l}\text { Số } \\
\text { lượng } \\
\text { thủ } \\
\text { tục }\end{array}$ & $\begin{array}{l}\text { Thời } \\
\text { gian } \\
\text { thực } \\
\text { hiện } \\
\text { (ngày) }\end{array}$ & $\begin{array}{c}\text { Chi } \\
\text { phí } \\
\text { (\% } \\
\text { thu } \\
\text { nhập) }\end{array}$ & $\begin{array}{l}\text { Số } \\
\text { lượng } \\
\text { quy } \\
\text { trình }\end{array}$ & $\begin{array}{l}\text { Thời } \\
\text { gian } \\
\text { thực } \\
\text { hiện } \\
\text { (ngày) }\end{array}$ & $\begin{array}{c}\text { Chi } \\
\text { phí } \\
\text { (\% } \\
\text { thu } \\
\text { nhập) }\end{array}$ & $\begin{array}{c}\text { Chỉ số } \\
\text { hô̂ trợ } \\
\text { tiếp cận } \\
\text { nguồn } \\
\text { lực đầu } \\
\text { vào }(0- \\
100)\end{array}$ & $\begin{array}{c}\text { Xếp } \\
\text { hạng hỗ } \\
\text { trợ tiếp } \\
\text { cận } \\
\text { nguồn } \\
\text { lực đầu } \\
\text { vào } \\
\text { (RANK) }\end{array}$ & $\begin{array}{c}\text { Chi } \\
\text { phí } \\
(\% \\
\text { giá trị } \\
\text { tài } \\
\text { sản) }\end{array}$ & $\begin{array}{l}\text { Chỉ số } \\
\text { chất } \\
\text { lượng } \\
\text { quản } \\
\text { trị đất } \\
\text { đai 0- } \\
30\end{array}$ \\
\hline Việt Nam & 8 & 16 & 5,6 & 10 & 166 & 0,5 & 88,2 & 27 & $0,6^{*}$ & 14 \\
\hline Philippines & 13 & 33 & 23,3 & 22 & 120 & 2,3 & 87,4 & 32 & 4,3 & 12,5 \\
\hline Thái Lan & 5 & 6 & 3 & 14 & 113 & $0,6^{*}$ & 98,7 & 6 & 7,2 & 19 \\
\hline Malaysia & 8 & 17 & 11,1 & 9 & 53 & 1,3 & $99,3^{*}$ & $4^{*}$ & 3,5 & 26,5 \\
\hline Indonesia & 11 & 13 & 5,7 & 18 & 200 & 4,5 & 87,3 & 33 & 8,3 & 15,5 \\
\hline Singapore & $2 *$ & $1,5^{*}$ & $0,4^{*}$ & 9* & $35,5^{*}$ & 3,3 & 91,8 & 19 & 2,9 & $28,5^{*}$ \\
\hline Campuchia & 9 & 99 & 53,4 & 20 & 652 & 3 & 57,5 & 146 & 4,3 & 7,5 \\
\hline
\end{tabular}

Chú thích: * giá trị chỉ số tốt nhất trong số các quốc gia so sánh - theo tùng tiêu chí đánh giá.

(Nguồn: WB, 2021; UNIDO, 2019; UNCTAD, 2020)

Nhóm tiêu chí này liên quan đến mức độ cắt giảm các thủ tục hành chính; khả năng ngăn ngừa các hành vi tiêu cực (tham nhũng, quan liêu, chính sách không minh bạch,...) làm gia tăng thời gian và chi phí thực hiện các thủ tục; cũng như tăng cường hỗ trợ kết nối với các cơ quan chuyên trách nhằm hỗ trợ doanh nghiệp một cách tối đa. Kết quả phân tích ở Bảng 4 cho thấy: xét về khía cạnh hỗ trợ khởi sự, Việt Nam có lợi thế với các nước ASEAN về chi phí khởi sự kinh doanh (ở mức 5,6\% thu nhập), nhưng số lượng thủ tục, thời gian thực hiện vẫn còn khá chậm (tương ứng $8 \div 16$ ngày).
Xét về khía cạnh hỗ trợ xin các loại giấy phép, Việt Nam làm khá tốt ở khâu số lượng quy trình và chi phí thực hiện (tương ứng 10 và $0,5 \%$ thu nhập), tuy vậy thời gian thực hiện còn khá chậm, các doanh nghiệp đầu tư vào các KKT, KCN ở Việt Nam trung bình mất tới 166 ngày để hoàn thành việc xin các loại giấy phép.

Xét về khía cạnh hỗ trợ tiếp cận các nguồn lực đầu vào (như nguồn nhân lực, cơ sở hạ tầng điện, nước). Việt Nam đạt được chỉ số 88,2 trên thang đo 100, tương đối tốt. Tuy nhiên, còn khoảng cách khá xa so với KKT, KCN ở Thái Lan, Malaysia, 
Singapore (chỉ số tương ứng là 98,7; 99,3 và 91,8). Cuối cùng, xét về khía cạnh hỗ trợ đăng ký tài sản, khả năng này giúp thúc đẩy việc chuyển nhượng đất đai, tài sản, khuyến khích đầu tư và cho phép các doanh nghiệp tiếp cận thị trường tín dụng chính thức. Có thể thấy: Việt Nam có lợi thế ở mặt này khi chi phí đăng ký chỉ tương đương $0,6 \%$ giá trị tài sản. Tuy vậy, chỉ số chất lượng quản trị tài sản ở các KKT, KCN Việt Nam vẫn còn tương đối thấp so với Malaysia, Singapore (14 so với 26,5 ; 28,5).

- Cạnh tranh về khả năng hỗ trợ tiếp cận tài chính và vận hành doanh nghiệp.

Nhóm tiêu chí này liên quan đến mức độ tạo thuận lợi cho các nhà đầu tư vận hành hoạt động kinh doanh tại KKT, KCN thông qua: minh bạch hóa các thông tin tín dụng và gia tăng quyền hợp pháp của người đi vay, người cho vay; giảm bớt các khoản thuế và các nghĩa vụ xã hội không cấp bách, đơn giản hóa quy trình nộp thuế; tăng cường mức độ thuận tiện trong quá trình xuất/nhập khẩu hàng hóa tại KKT, KCN. Kết quả phân tích ở Bảng 7 cho thấy: xét về khía cạnh hỗ trợ tiếp cận tín dụng, Việt Nam đứng đầu khu vực về chỉ số độ sâu của thông tin tín dụng và mức độ dễ dàng tiếp cận tín dụng (lần lượt đạt mức 8 và 80,0). Ngược lại, đây được xem như điểm yếu nhất của các KKT, KCN ở Philippines (với chỉ số sức mạnh của quyền hợp pháp đạt mức 1 trên thang đo 12).

Xét về khía cạnh nộp thuế và các nghĩa vụ xã hội, tuy các KKT, KCN ở Việt Nam đã nỗ lực cắt giảm các khoản mục thuế và chi cho nghĩa vụ xã hội của doanh nghiệp xuống còn trung bình 6 khoản. Nhưng thời gian thực hiện lại là điểm yếu cố hữu, cụ thể Việt Nam xếp hạng thấp nhất trong số các nước ASEAN với tổng thời gian nộp thuế và nghĩa vụ xã hội lên đến 384 ngày. Mức thuế và chi cho nghĩa vụ xã hội vẫn ở mức tương đối cao (tương ứng 37,6\% lợi nhuận), chỉ thấp hơn Malaysia $(38,7 \%)$ và Philippines $(43,1 \%)$. Xét về khía cạnh thúc đẩy giao dịch thương mại qua biên giới, thời gian xuất khẩu (55 giờ, chỉ tốt hơn duy nhất Indonesia - 56 giờ) và chi phí nhập khẩu (373 USD, thấp hơn rất nhiều so với Thái Lan, Malaysia, Singapore và Campuchia) là hai khía cạnh Việt Nam cần cải thiện nhanh chóng.

- Cạnh tranh về khả năng hỗ trợ các vấn đề khó khăn của doanh nghiệp.

Nhóm tiêu chí này liên quan đến việc: xây dựng các cơ chế chính sách, luật hiệu quả và minh

Bảng 7. Cạnh tranh về khả năng hỗ trợ khởi sự kinh doanh và hỗ trợ tiếp cận địa điểm.

\begin{tabular}{|c|c|c|c|c|c|c|c|c|c|c|}
\hline \multirow[b]{2}{*}{ Nước } & \multicolumn{3}{|c|}{$\begin{array}{l}\text { Khả năng hỗ trợ tiếp } \\
\text { cận tín dụng }\end{array}$} & \multicolumn{3}{|c|}{$\begin{array}{c}\text { Nộp thuế và các nghĩa vụ xã } \\
\text { hội }\end{array}$} & \multicolumn{4}{|c|}{$\begin{array}{l}\text { Khả năng thúc đẩy giao dịch } \\
\text { thương mại qua biên giới }\end{array}$} \\
\hline & $\begin{array}{l}\text { Chỉ số } \\
\text { độ sâu } \\
\text { của } \\
\text { thông } \\
\text { tin tín } \\
\text { dụng } \\
(0-8)\end{array}$ & $\begin{array}{c}\text { Chỉ số } \\
\text { sức } \\
\text { mạnh } \\
\text { của } \\
\text { quyền } \\
\text { hợp } \\
\text { pháp } \\
(0- \\
12)\end{array}$ & $\begin{array}{l}\text { Mức } \\
\text { độ dễ } \\
\text { dàng } \\
\text { tiếp } \\
\text { cận } \\
\text { tín } \\
\text { dụng }\end{array}$ & $\begin{array}{l}\text { Số lượng } \\
\text { khoản } \\
\text { nộp/trích }\end{array}$ & $\begin{array}{l}\text { Thời } \\
\text { gian } \\
\text { thực } \\
\text { hiện } \\
\text { (ngày) }\end{array}$ & $\begin{array}{l}\text { Tổng } \\
\text { thuế } \\
\text { suất } \\
\text { (\% lợi } \\
\text { nhuận) }\end{array}$ & $\begin{array}{l}\text { Thời } \\
\text { gian } \\
\text { xuất } \\
\text { khẩu } \\
\text { (giờ) }\end{array}$ & $\begin{array}{l}\text { Chi } \\
\text { phí } \\
\text { xuất } \\
\text { khẩu } \\
\text { (USD) }\end{array}$ & $\begin{array}{l}\text { Thời } \\
\text { gian } \\
\text { nhập } \\
\text { khẩu } \\
\text { (giờ) }\end{array}$ & $\begin{array}{l}\text { Chi } \\
\text { phí } \\
\text { nhập } \\
\text { khẩu } \\
\text { (USD) }\end{array}$ \\
\hline Việt Nam & 8* & 8 & $80,0^{*}$ & 6 & 384 & 37,6 & 55 & 290 & 56 & 373 \\
\hline Philippines & 7 & 1 & 40,0 & 13 & 171 & 43,1 & 42 & 456 & 120 & 690 \\
\hline Thái Lan & 7 & 7 & 70,0 & 21 & 229 & 29,5 & 44 & 223 & 50 & 233 \\
\hline Malaysia & $8^{*}$ & 7 & 75,0 & 9 & 174 & 38,7 & 28 & 213 & 36 & $213^{*}$ \\
\hline Indonesia & $8^{*}$ & 6 & 70,0 & 26 & 191 & 30,1 & 56 & $211^{*}$ & 99 & 383 \\
\hline Singapore & 7 & 8 & 75,0 & $5^{*}$ & $64^{*}$ & $21,0^{*}$ & $10^{*}$ & 335 & 33 & 220 \\
\hline Campuchia & 6 & $10^{*}$ & $80,0 *$ & 40 & 173 & 23,1 & 48 & 375 & $8^{*}$ & 240 \\
\hline
\end{tabular}

Chú thích: * giá trị chỉ số tốt nhất trong số các quốc gia so sánh - theo tùng tiêu chí đánh giá.

(Nguồn: WB, 2021; UNIDO, 2019; UNCTAD, 2020) 
bạch nhằm giải quyết chính xác, nhanh chóng các tranh chấp phát sinh; minh bạch hóa các thông tin về hoạt động của doanh nghiệp nội địa nhằm tạo ra môi trường cạnh tranh công bằng, từ đó thúc đẩy tất cả doanh nghiệp trong KKT, KCN phát triển; cuối cùng là phân bố lại hiệu quả các tài sản và nguồn lực của doanh nghiệp trong trường hợp bị phá sản.

Kết quả phân tích ở Bảng 8 cho thấy: xét về khía cạnh bảo vệ nhà đầu tư, Việt Nam có chỉ số sức mạnh bảo về nhà đầu tư khá thấp (đạt mức 27 trên thang 50), trong khu vực ASEAN chỉ cao hơn Campuchia. Tương ứng xếp hạng mức độ an tâm nhà đầu tư, Việt Nam cũng chỉ xếp thứ 97.

Tiếp đến, xét về khả năng giải quyết các tranh chấp hợp đồng, thời gian và chi phí xử lý của các doanh nghiệp hoạt động ở các KKT, KCN Việt Nam ở mức trung bình (lần lượt là 400 ngày và $29 \%$ giá trị thu hồi), tuy nhiên chỉ số chất lượng quy trình tư pháp lại khá thấp (ở mức 7,5 trên thang đo 18). Đáng chú ý, khía cạnh giải quyết tranh chấp hợp đồng này được xem là những điểm yếu trầm trọng của các KKT, KCN ở Philippines (thời gian xử lý lên đến 962 ngày) và Campuchia (chi phí lên đến 103,4\% giá trị thu hồi và chỉ số chất lượng quy trình tư pháp cũng chỉ ở mức 4,5).
Cuối cùng, xét về khả năng giải quyết phá sản doanh nghiệp, thời gian thực hiện ở các KKT, KCN Việt Nam thường phải tốn gấp đôi, thậm chí gấp ba ở các nước ASEAN khác; tỷ lệ thu hồi tài sản cũng khá thấp (chỉ đạt 21,3 cents trên 1 USD tài sản).

\section{Kết luận và một số đề xuất}

Trong bối cảnh các nền kinh tế trong khu vực đang ráo riết cải cách nhằm nâng cao hiệu quả hoạt động của các $\mathrm{KKT}, \mathrm{KCN}$, vấn đề nghiên cứu về so sánh năng lực cạnh tranh lại càng thu hút sự quan tâm của giới nghiên cứu lẫn các nhà quản lý ở các nước ASEAN. Trong nghiên cứu này, thông qua việc sử dụng đồng thời hai phương pháp nghiên cứu định tính và định lượng, nghiên cứu đã giúp chỉ ra các điểm mạnh và điểm yếu của các KKT, KCN ở Việt Nam so với các nước khác, một số vấn đề cụ thể cần được xúc tiến cải cách gồm:

Trước tiên, liên quan đến khả năng hỗ trợ khởi sự kinh doanh, số lượng thủ tục, thời gian thực hiện vẫn còn khá chậm. Điều này chủ yếu xuất phát từ bộ máy làm thủ tục còn khá cồng kềnh, doanh nghiệp phải liên hệ nhiều đơn vị ở nhiều nơi khác nhau khi bắt đầu triển khai kinh doanh (Bộ KH\&ĐT, 2020). Các KKT, KCN cần tiến

Bảng 8. Cạnh tranh về khả năng hỗ trợ các vấn đề khó khăn của doanh nghiệp.

\begin{tabular}{|c|c|c|c|c|c|c|c|c|}
\hline \multirow[b]{2}{*}{ Nước } & \multicolumn{2}{|c|}{ Bảo vệ nhà đầu tư } & \multicolumn{3}{|c|}{ Giải quyết tranh chấp hợp đồng } & \multicolumn{3}{|c|}{ Giải quyết phá sản DN } \\
\hline & $\begin{array}{c}\text { Chỉ số } \\
\text { sức } \\
\text { mạnh } \\
\text { bảo vệ } \\
\text { nhà đầu } \\
\text { tư (0- } \\
\text { 50) }\end{array}$ & $\begin{array}{l}\text { Xếp hạng } \\
\text { mức độ an } \\
\text { tâm nhà } \\
\text { đầu tư } \\
\text { (RANK) }\end{array}$ & $\begin{array}{l}\text { Thò̀i } \\
\text { gian } \\
\text { thực } \\
\text { hiện } \\
\text { (ngày) }\end{array}$ & $\begin{array}{l}\text { Chi phí } \\
\text { (\% giá } \\
\text { trị thu } \\
\text { hồi) }\end{array}$ & $\begin{array}{l}\text { Chỉ số chất } \\
\text { lượng quy } \\
\text { trình tư } \\
\text { pháp (0- } \\
\text { 18) }\end{array}$ & $\begin{array}{l}\text { Thời } \\
\text { gian } \\
\text { thực } \\
\text { hiện } \\
\text { (ngày) }\end{array}$ & $\begin{array}{l}\text { Chi } \\
\text { phí } \\
\text { (\% } \\
\text { tài } \\
\text { sản) }\end{array}$ & $\begin{array}{c}\text { Tỷ lệ } \\
\text { thu hồi } \\
\text { (cents } \\
\text { trên } 1 \\
\text { USD) }\end{array}$ \\
\hline Việt Nam & 27 & 97 & 400 & 29,0 & 7,5 & 5,0 & 14,5 & 21,3 \\
\hline Philippines & 30 & 72 & 962 & 31,0 & 7,5 & 2,7 & 32,0 & 21,1 \\
\hline Thái Lan & 43 & 3 & 420 & $16,9^{*}$ & 8,5 & 1,5 & 18,0 & 70,1 \\
\hline Malaysia & $44^{*}$ & $2 *$ & 425 & 37,9 & 13,0 & 1,0 & 10,0 & 81,0 \\
\hline Indonesia & 35 & 37 & 403 & 70,3 & 8,9 & 1,1 & 21,6 & 65,5 \\
\hline Singapore & 43 & 3 & $164^{*}$ & 25,8 & $15,5^{*}$ & $0,8^{*}$ & $4,0^{*}$ & $88,7^{*}$ \\
\hline Campuhia & 20 & 128 & 483 & 103,4 & 4,5 & 6,0 & 18,0 & 14,6 \\
\hline
\end{tabular}

Chú thích: * giá trị chỉ số tốt nhất trong số các quốc gia so sánh - theo tùng tiêu chí đánh giá. 
tới xây dựng hệ thống "một cửa" trong việc xử lý các thủ tục để đẩy nhanh tốc độ.

Tương tự, liên quan đến vấn đề nộp thuế và các nghĩa vụ xã hội, thời gian xử lý các thủ tục về nộp thuế vẫn còn mất khá nhiều thời gian của doanh nghiệp. Chi phí vẫn còn tương đối cao có thể xuất phát từ việc tần suất kiểm tra, thúc đẩy thực hiện các nghĩa vụ về thuế và nghĩa vụ xã hội khá cao, cũng như việc hạn chế nhũng nhiễu vẫn còn chưa thực sự triệt để.

Tiếp đến, thời gian xuất khẩu còn khá dài và chi phí nhập khẩu khá cao. Tuy Việt Nam có hệ thống cảng biển xuất nhập khẩu khá dày từ Bắc vào Nam, nhưng chỉ có một số trong đó hoạt động hiệu quả. Dẫn đến doanh nghiệp thường phải đưa hàng hóa vận chuyển khá xa, gây tốn kém về mặt thời gian và chi phí là điều tất yếu. Cuối cùng, liên quan đến khả năng giải quyết phá sản doanh nghiệp, các KKT, KCN ở Việt Nam dường như vẫn chưa thực sự quan tâm đến vấn đề này nên thời gian thực hiện và hiệu quả vẫn còn rất thấp.

Tuy nghiên cứu đạt được những kết quả nhất định, nhưng vẫn tồn tại một số hạn chế. Do những giới hạn về nguồn dữ liệu có thể thu thập được, nên hệ thống tham số phân tích vẫn chưa thực sự trọn vẹn. Do đó, cần có những nghiên cứu tiếp theo so sánh làm rõ các khía cạnh khác của năng lực cạnh tranh KKT, KCN, như: các yếu tố sẵn có (vị trí địa lý, tài nguyên tự nhiên); năng lực của bộ máy quản lý nhà nước; hạ tầng xã hội và kỹ thuật; các chính sách tài khóa, đầu tư, tín dụng, cơ cấu.

\section{Đóng góp của các tác giả}

Tác giả 1 đề xuất ý tưởng, đề cương và hoàn thiện bản thảo bài báo; tác giả 2 và 4 triển khai các nội dung và hoàn thành bản thảo bài báo; tác giả 3 đánh giá chỉ tiêu cạnh tranh.

\section{Tài liệu tham khảo}

Aggarwal, A. (2019). Leveraging SEZs for Regional Integration in ASEAN: A Synergistic Approach. Asian Survey, 59(5), 795-821.

ASEAN Secretariat. (2020). ASEAN Key Figures 2019.

Ayman, F. M. (2020). Special Economic Zones in ASEAN: Opportunities for US Investors. ASEAN Briefing.
Bộ Kế hoạch và Đầu Tư. (2020). Báo cáo thực trạng các khu kinh tế, Khu công nghiệp ở Việt Nam trong giai đoạn 2016-2020.

Bogoviz, A. V., Ragulina, Y.V., \& Kutukova, E. S. (2016). Economic zones as a factor of increased economic competitiveness of the region. International Journal of Economics and Financial Issues, 6(8S).

CARI Captures. (2020). Southeast Asia's FDI inflows increased 5\% in 2019.

Chia, S. Y. (2014). The ASEAN economic community: Progress, challenges, and prospects. In $A$ World Trade Organization for the 21st Century. Edward Elgar Publishing.

Farole, T., \& Akinci, G. (Eds.). (2011). Special economic zones: Progress, emerging challenges, and future directions. World Bank Publications.

Hsu, M. S., Lai, Y. L., \& Lin, F. J. (2013). Effects of industry clusters on company competitiveness: Special economic zones in Taiwan. Review of Pacific Basin Financial Markets and Policies, 16(03), 1350017.

Hiệu, N. T., \& Lệ, L. T. (2021). Nghiên cứu các nhân tố ảnh hưởng đến năng lực cạnh tranh của Khu Kinh tế Nghi Sơn, Thanh Hóa. Tạp chí Khoa học Kĩ thuật Mỏ - Địa chất tập, 62(2), 73-82.

Ishida, M. (2009). Special economic zones and economic corridors. ERIA Discussion Paper Series, 16, 2009.

Krainara, C., \& Routray, J. K. (2015). Cross-border trades and commerce between Thailand and neighboring countries: Policy implications for establishing special border economic zones. Journal of Borderlands Studies, 30(3), 345363.

Nghị định 82/2018/NĐ-CP. (2018). Nghị định quy định về quản lý Khu công nghiệp và Khu kinh tế, Chính Phủ.

Porter, M. E., (2011).Competitive advantage of nations: creating and sustaining superior performance. simon and schuster.

TrendEconomy, (2021). Annual International Trade Statistics by Country (HSO2).

Đỗ Minh Triết, (2019). Tác động của chỉ số năng lực cạnh tranh cấp tỉnh đến thu hút vốn đầu tư trực tiếp nước ngoài vào các tỉnh phía Nam Việt Nam. 
UNCTAD, (2020). ASEAN Investment Report 2019. United Nations Conference on Trade and Development.

UNIDO, (2019). Economic Zones in the ASEAN Industrial Parks, Special Economic Zones, Ecoindustrial Parks, Innovation districts as strategies for industrial competitiveness. United Nations Industrial Development Organisation.

Wahyuni, S., \& SA, E. A. (2010). What Investors Think About Our FTZ Areas? Case Study On Batam, Bintan, Karimun. In Paper submitted to the BBK Conference, Bali.

Wahyuni, S., Astuti, E. S., \& Utari, K. M. (2013). Critical Outlook at Special Economic Zone in Asia: A Comparison Between Indonesia, Malaysia, Thailand and China.Journal of Indonesian Economy and Business, 28(3), 336-346.

Wahyuni, S., Djamil, I. K., Astuti SA, E. S., \& Mudita, T. (2010). The study of regional competitiveness in Batam, Bintan and Karimun. International Journal of Sustainable Strategic Management,2(3), 299316.

Wang, J. (2013). The economic impact of special economic zones: Evidence from Chinese municipalities. Journal of development economics, 101, 133-147.

Warr, P., \& Menon, J. (2016). Cambodia's special economic zones.Journal of Southeast Asian Economies, 273-290.

World Bank, (2021). Doing Business 2019: Reforming through Difficult Times. World Bank and IFC Publications.

World Economic Forum, (2020). Competitiveness Report 2018-2019. World Economic Forum.

Zeng, D. Z. (Ed.). (2010). Building engines for growth and competitiveness in China: Experience with special economic zones and industrial clusters. World Bank Publications. 